\title{
Apresentação da edição especial comemorativa dos 50 anos da Revista de Antropologia
}

A Revista de Antropologia, primeiro periódico especializado em nossa disciplina publicado no Brasil, comemora meio século de existência. Fundada em 1953 pelo professor Egon Schaden, já foi o órgão oficial da Associação Brasileira de Antropologia, da Associação Brasileira de Sociologia e, atual mente, é publicação do D epartamento de Antropologia da FFLCH -USP.

Ao longo desses anos - desde os primeiros números, de feitura artesanal, até o presente momento - , a Revista atravessou várias fases, tendo passado por mudanças deformato e política editorial, mas sempre pautada pelo objetivo queestá expresso em suas primeiras páginas: "a divulgação e discussão de temas, resultados de pesquisas e model os teórico-metodológicos próprios da antropologia em suas diversas áreas e interfaces com disciplinas afins, a partir de textos inéditos, de forma a proporcionar aos leitores um panorama sempre atual izado das questões mais relevantes de seu campo de pesquisa e reflexão, no país e no exterior".

Para marcar a data, a Comissão Editorial programou esta edição comemorativa com entrevistas, artigos e depoimentos al usivos à trajetória da Revista de Antropologia e ao papel que ela representa no campo das ciências sociais no Brasil.

0 desafio para este número seria chegar ao tom adequado: teria de reconhecer e prestar a justa homenagem não apenas a seu fundador, Egon Schaden, como também aos demais editores com suas respectivas 
Revista de Antropologia, São Paulo, U SP, 2003, v. 46 № 2.

Comissões Editoriais e equipes técnicas, mas sem imprimir um viés demasiadamente memorialista: afinal de contas, o "presente etnográfico" não é apenas a retórica característica das narrativas mais emblemáticas de nossa disciplina, mas reflete a ênfase na contemporaneidade de suas reflexões.

A entrevista com João Baptista Borges Pereira, assim como a maior parte dos depoimentos e os artigos de M ariza Corrêa e de Júlio Assis Simões e Fernanda Peixoto recuperam os primeiros tempos da Revista, situando-a no contexto específico de seu surgimento e processo de consolidação; já o texto de Paula M ontero realiza um balanço de sua fase mais recente. A entrevista com Bento Prado Júnior, sobre PierreC lastres, responde à intenção de fazer com que este número trouxesse informações, a partir de uma perspectiva diferente, sobre um autor - com passagem pelo D epartamento de Antropologia da U SP e contato com al guns de seus integrantes - cuja obra volta a ser objeto de interesse acadêmico e editorial. 0 artigo de $\mathrm{M}$ arcio $\mathrm{G}$ oldman compõe o quadro para ressaltar não apenas a presença e importância da etnografia, ao longo das páginas da Revista desde os primeiros números (com todas as facetas, conotações e leituras que este termo implica), como o papel central e específico que ocupa na prática e na análise antropológicas.

Fecha este volume, a exemplo do que foi feito no número 21 (1978), um índice com todos os autores e textos publicados desde o primeiro número até a presente data, organizado por Francisco Simões Paes, que também colaborou, juntamente com Sylvia Caiuby N ovaes, na seleção de fotos, gentilmente cedidas por Erika e M arina Schaden, filhas de Egon Schaden, a quem prestamos nosso agradecimentos.

Encerro esta apresentação com o registro das pessoas diretamente envolvidas na publicação da revista: 
Revista de Antropologia, São Paulo, U SP, 2003, v. 46 № 2.

1953-1978: Diretor: Egon Schaden. Conselho de Redação (19531955): Plínio Ayrosa, H erbert Baldus, O távio da Costa Eduardo, Florestan Fernandes, Antônio Rubbo Muller e Gioconda M ussolini. Secretário-Tesoureiro: Renato Jardim M oreira, substituído em 1954 por Eunice Ribeiro (depois D urham) ${ }^{1}$. Conselho Editorial (1978): H unaldo Beiker, João Baptista Borges Pereira e Renate Brigitte Viertler.

1979-1990: Diretor: João Baptista Borges Pereira. Consel ho Editorial: H unaldo Beiker, Lux Vidal, Liana SálviaTrindade, Renate Brigitte Viertler, Amadeu Duarte Lanna, Eunice Ribeiro D urham (a partir de 1982), José G uilherme $C$ antor $M$ agnani e $M$ anuela $C$ arneiro da Cunha (a partir de 1986). Secretário: Renato da Silva Q ueiroz.

1991-1997: Editora Responsável: Paula M ontero. Comissão Editorial: João Baptista Borges Pereira, Aracy Lopes da Silva e Lilia M oritz Schwarcz. Secretária: Soraya G ebara².

1997-2004: Editor Responsável: José Guilherme C antor M agnani. C omissão Editorial: John C owart D awsey eSylvia C aiuby N ovaes, substituída em 2003 por Júlio Assis Simões. Secretária: Soraya G ebara.

A Revista de Antropologia, plenamente consolidada, com um ConseIho Editorial de projeção no país e no exterior, devidamente indexada e com arbitragem, tornou-se também, em 1999, a primeira do gênero a fazer parte da SciELO (Scientific Electronic Library O nline - http:// www. sciel 0 . br), biblioteca virtual de revistas científicas brasileiras em formato eletrônico. A iniciativa não se restringe à possi bilidade de inaugurar uma nova escala de divul gação e de permitir o acesso a todo seu conteúdo: trata-se da aplicação de um projeto mais amplo, resultado de parceria entre a Fundação de Amparo à Pesquisa do Estado de São Paulo (Fapesp) e o Centro Latino-Americano e do Caribe de Informações em Ciências da Saúde (Bireme), cujo propósito é fornecer infra-estrutura necessária para pesquisa científica. 
Revista de Antropologia, São Paulo, U SP, 2003, v. 46 № 2.

Essa inclusão no sistema SciELO e a incorporação das normas de editoração do programa Q ualis constituem os mais recentes ajustes para que a Revista de Antropologia, fiel a sua história e aos objetivos definidos por sua missão, esteja sempre em consonância com as exigências postas pelo campo de reflexão de nossa disciplina.

\author{
Pela Comissão Editorial \\ José G uilherme Cantor M agnani \\ Editor Responsável
}

\title{
N otas
}

1 De 1956 até 1972, não há referência ao Conselho de Redação. D e 1972 a 1977, a publicação da Revista é interrompida, sendo retomada em 1978, com um novo Conselho Editorial.

2 A partir de 1991 até o presente, há uma distinção entre a Comissão E ditorial, encarregada da confecção da Revista, e o Conselho Editorial, mais amplo, formado por antropólogos de fora do D epartamento de Antropologia da FFLCH -U SP. 
Revista de Antropologia, São Paulo, U SP, 2003, v. 46 no 2.

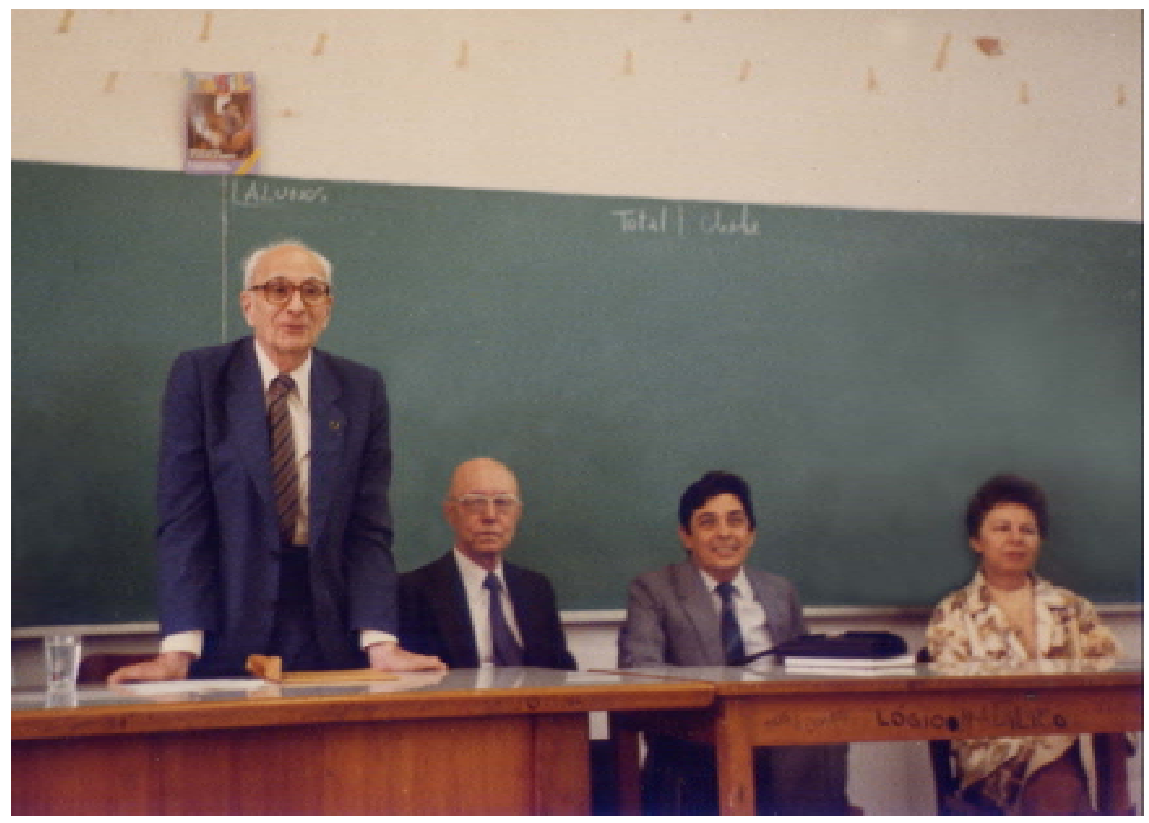

Egon Schaden, João Baptista Borges Pereira e Eunice Ribeiro D urham recebem Claude Lévi-Strauss na U SP, em 1985. 